\title{
Bayesian mapping of stream-bed sediment samples, grouped by watershed
}

\author{
BRONWEN WANG, KARL J ELLEFESEN AND \\ MARGARET A GOLDMAN
}

USGS

Presenting Author: bwang@usgs.gov

Stream sediments integrate the geochemical signature of lithologies in a watershed. The link between bed-sediment chemistry and lithology make watershed boundaries a natural structure for grouping geochemical data from stream sediments. If there are only a few samples in each watershed, then summary statistics for a watershed have a high degree of uncertainty. Consequently, maps based on those statistics may have spurious values in those watersheds. This problem may be mitigated by using the grouping to make a spatially smooth map. The smoothing algorithm is implemented with a Bayesian method because it has several advantages. First, the Bayesian method can account for concentrations that are measured by different analytical methods. Second, the method can account for concentrations that are beyond the lower and upper reporting limits for an analytical method. Finally, the method can calculate the uncertainty in the map, which is crucial to its proper interpretation.

The method is applied to gold concentrations from 767 samples of stream-bed sediments collected from 215 watersheds within the Taylor Mountains quadrangle in southwestern Alaska (United States). The average number of samples per watershed is 3.6; for such sparse sampling, Bayesian mapping is appropriate. The smoothed map of mean gold concentration is compared to three sets of geologic data. The comparisons show that watersheds with high mean gold concentrations are spatially associated with locations of known gold mineralization, with rock samples that have high gold concentration, and with field samples of heavy minerals that include visable gold grains. The interpretation of these comparisons is that the map of mean gold concentration accurately represents the gold concentration in the Taylor Mountains quadrangle.

In addition to stream-bed sediments grouped by watershed, this method may be applied to any univariate Earth science data that are appropriately grouped by region. For example, it might be used to map, by watershed, the concentrations of a dissolved contaminant. 